\title{
Role of Ilizarov External Fixator in charcot osteoarthropathy: Systemic Review
}

\author{
A.H.Adawy, M.A.Meselhy, S.A.Shawlah, and M.M.Abed \\ Orthopedic Surgery Dept., Faculty of Medicine, Benha Univ., Benha, Egypt \\ E-Mail: Moataz@gmail.com
}

\begin{abstract}
Charcot is a progressive disabling disorder that requires early diagnosis and attention to prevent further complicating factors. Such factors include a "rocker bottom" talus, which can lead to chronic plantar wounds, subsequent infectious processes with frequent hospitalization and increasing risks for lower limb amputation. Those point for this systemic survey may be with spotlight on the part of Ilizarov outside fixator to charcot osteoarthropathy, Furthermore with examine the controversies may be it of a quality in this kind of patients or not. An PubMed look might have been done with those pivotal word "Charcot foot, neuropathic arthropathy, charcot arthropathy." we Might follow something like 400 up and coming papers on the liable. Article qualification might have been evaluated freely Toward every last bit writers. Purposes behind prohibition from claiming articles In light of title or unique were non first information (e. G. , editorials, guidelines, What's more comments), nonclinical articles (e. G. , specialized foul or creature studies), body of evidence reports, Furthermore articles not composed in english dialect. Those methods talked about in the display Audit bring both been indicated on make Exceptionally viable medicine of the midfoot cf. Those current information ahead these methods were as well restricted to backing whatever outcome-based correlations. These methods ought further bolstering a chance to be examined further on give masters for Scrutinize with supplement their individual tact.
\end{abstract}

Keywords: Ilizarov, External Fixator, Charcot, Osteoarthropathy.

\section{Introduction}

Charcot may be An progressive incapacitating confusion that obliges right on time finding Furthermore thoughtfulness regarding forestall further entangling elements. Such elements incorporate a "rocker bottom" talus, which could prompt unending plantar wounds, ensuing irresistible techniques with incessant hospitalization What's more expanding dangers to bring down appendage removal [1].

Charcot, clinched alongside 1883, initial depicted charcot neuroarthropathy happening over patients with tabes dorsalis. Charcot neuroarthropathy might have been not referred to to be connected with diabetes until jordan noted over 1936 diabetic neuroarthropathy will be An ruinous procedure influencing those hard parts of a denervated joint. Diabetes mellitus will be currently those principle reason for charcot neuroarthropathy [2].

Clinched alongside both those made What's more making universes the predominance of the illness may be some place in the extend of 0. $08 \%$ Also $7.5 \%$ over patients for diabetes mellitus, armstrong et al need uncovered the pervasiveness about charcot foot on a chance to be harshly $0.16 \%$ all things considered masses What's more around $13 \%$ in the secondary peril diabetic patients exhibiting will a foot office [3].

Clinically after watching an absence from claiming ordinary foot sensation, vicinity of ulceration, and the vicinity from claiming foot disfigurement due to joint subluxations / dislocations [4].

Eichenholtz arrangement from claiming charcot joint arthropathy:. Stage 1: improvement phase, described Toward discontinuity about bones and cartilage, joint effusions, subluxation Furthermore dislocation, delicate tissue edema, hyperemia, bone resorption, What's more intra-articular fractures.

Phase 2: combination phase, portrayed Toward diminished delicate tissue oedema, recuperating of fractures, and association for bone pieces.

Stage 3: reproduction phase, portrayed by new bone creation and remodeling about bone. [5].

Those questionable address is: during the thing that phase from claiming charcot ought to patients experience reconstructive surgery? simon and partners performed arthrodesis with respect to early phase charcot patients with no quick alternately long haul difficulties. Constantly on patients regained the level from claiming strolling capacity they encountered Awhile ago. However, obsession from claiming bone in the zone about disintegration could make was troublesome Also at times not conceivable because of poor people nature of the bone, which might prompt a secondary rate from claiming combination disappointment. It might be in the surgeon's greatest advantage on sit tight until those tolerant need a after the fact phase for charcot What's more combination will be exhibit. [6]. $40 \%$ from 
claiming patients for charcot midfoot ailment who needed been administered fundamentally with traditionalist forethought might require restorative methodology. Arthrodesis may be viewed Similarly as a choice to those medication for charcot arthropathy in the combination Furthermore remaking periods best. Charcot may be a multiplane disfigurement. Whether those midfoot is affected, an arthrodesis will be exact viable for tending to the greater part planes about disfigurement. In those charcot is influencing the hindfoot, An talectomy with An pantalar arthrodesis will assistance position those foot suitably Furthermore at the end of the day deliver the sum planes of the disfigurement [7].

Patients who need repetitive unending ulcerations with radiographic proof for plantar prominences because of charcot might make hopefuls for exostectomy of the bony disfigurement. Surgeons could perform exostectomy for Possibly a longitudinal average alternately longitudinal parallel entry point alongside full thickness analyzation of the bony structure. [8]. Removal might appear to be that once a tolerant need An disfigured foot that obliges extraordinary supervision, An major removal might make that's only the tip of the iceberg expense viable over reproduction. Late dissection exhibits that deep rooted fetches to real easier limit amputations will be over three times higher over the costs for patients undergoing remaking. The cosset for An tolerant following removal relies looking into three characteristics: those sort about prosthetic device, the level about appendage misfortune and the utilitarian ability of the distinctive [9].

All around On charcot illness, the bone stock may be poor Also external fixation provides for exceptional weight lesquerella fixation disappointments Furthermore fragile tissue confusions. Fitting fixation could be testing What's more troublesomeness. Fixation could happen freely or to mix for internal screws, inner part plate(s), outside indirect obsession, intramedullary nail What's more Steinmann pins. Consolidation of inside Furthermore outside obsession. This permits stress protecting of the arthrodesis site, aids Previously, avoidance about bowing Furthermore torsional forces, and acts Concerning illustration a impediment with unseemly weightbearing [10]. Because of its capacity should right multiplanar deformities for osteopenic bone considerably in the vicinity of open wounds, those hardware (Ilizarov) outside obsession will be favored for
A large portion about charcot foot and lower leg reconstructions [11]. Indications for Use of External Fixation:

- Midfoot/hindfoot/ankle instability

- Non-reducible bony deformity

- Bony defect (with or without osteomyelitis(

- Soft-tissue ulceration (with or without infection) [11].

The aim of this systemic review is to spotlight on the role of Ilizarov external fixator in Charcot osteoarthropathy, and to discuss the controversies is it of a value in this type of patients or not.

\section{Materials and methods}

A PubMed look might have been done with those pivotal word "Charcot foot, neuropathic arthropathy, charcot arthropathy. " we Might follow regarding 400 up and coming papers on the subject. Electronic database might have been deliberately searched to writing examining those history, pathophysiology, assessment, imaging methods, finding including osteomyelitis, classification, Furthermore oversaw economy for $\mathrm{CN}$. They connected no confinements with respect to production date.

Article qualification might have been evaluated freely Toward the greater part creators. Purposes behind prohibition from claiming articles In view of title alternately conceptual were non first information (e. G. , editorials, guidelines, Also comments), nonclinical articles (e. G. , specialized foul or creature studies), case reports, Also articles not composed done english dialect.

Every one writers freely picked those The majority up and coming papers around target topics bringing about those ID number for 59 "most pertinent" articles. Together they examined Furthermore compared the pertinent data from the sum these sources with our clinical act Also included them in this Audit.

Those essential Examine investigations news person starting with january 2006 should Walk 2019 were gathered from those PubMed national Institutes for wellbeing database. Main investigations reporting weight the outcomes about surgical intercessions used to treat charcot neuroarthropathy of the foot were examined, and main first Examine distributed for peer-reviewed diaries with information from $>3$ subjects might have been included.

They best recognized investigations composed to english for human subjects. They led searches with those assistance of a proficient curator. Those keywords utilized to those scan incorporated "Charcot," "arthropathy," "neurogenic," "surgery," 
"neuroarthropathy. ". Investigations worried for the medication of charcot deformities of the midfoot alternately the midfoot for conjunction with other ranges were broke down in the available study. To each study, we recorded the number about patients, downright number about surgeries performed, intend tolerant age, Furthermore sexual orientation circulation. Tolerant aspects for example, muscle to impostor list Also comorbidities for example, diabetic status (type 1 , sort 2, or nondiabetic) were gathered.

The surgical methodology utilized within every investigation and whatever Incorporation alternately avoidance criteria utilized for surgery were recorded. Those system for postoperative management and the Normal catch up time were recorded.

Finally, As far as those surgical outcomes, we recorded those postoperative walking status of the patients and the frequency about jolt alternately screw movement What's more wire, pin, or jolt breakage, hard combination (the fancied result to the greater part procedures), ensuing amputation, pin track infection, Furthermore preoperative and postoperative ulcers. The capacity with ambulate might have been recorded with respect to a for every tolerant groundwork. On account some patients needed required $>1$ surgery, they recorded the difficulties on a for every surgery support. Some majority of the data once these conclusions might have been missing; thus, those ambulation Furthermore muddling rates are accounted to the individuals patients for whom the information were accessible.

Investigations were just incorporated In information in regards these parameters required been news person independently to every last one of patients in the contemplate. In the investigations needed included patients who needed gained medicine for deformities not including those midfoot, such might have been the situation for A percentage investigations viewing multilevel outside fixation, best the information to those methods directing, including the midfoot were incorporated in the meta-analysis.

Assuming that such An investigation required not included differentiate effects to each tolerant (ie, accounted the aggregate amount for amputations to every one patients in the consider without including differentiate information for each patient), the contemplate might have been excluded. Those investigations were also obliged on bring An least for 3 patients undergoing medicine for midfoot deformities to be incorporated in the meta-analysis.
Those primary methods included in the display survey were average section combination Also multilevel outside fixation, a result mossycup oak of the investigations identifier in the information hunt required incorporated these methods. Information concerning those results of these investigations would recorded later in the examine.

2. 1. Factual dissection. We performed An meta-analysis for our information. Irregular impacts models were manufactured with gauge those rates for postoperative removal and hard combination on estimate the rates from claiming difficulties same time representing heterogeneity. Woods plots and pipe plots were drawn for each outcome, Furthermore heterogeneity might have been evaluated Also depicted utilizing Cochran's Q What's more I2. Those difference between investigations might have been assessed utilizing the irregular impacts model. Every last bit measurable Investigation might have been performed utilizing the r Factual bundle.

\section{Results}

The search yielded 136 reports. All abstracts were examined, and 111 were discarded, either because they were not primary studies of Charcot neuroarthropathy of the foot or because they had not exclusively included patients with CF. The remaining 25 full texts were read, and 3 were discarded because they had included patients who had not undergone surgery for Charcot neuroarthropathy and had not provided separate results for the Charcot patients receiving surgery.

Of the 22 studies, 7 were included in the outcome analysis for review. These were studies with data regarding surgical correction of midfoot deformities. The remaining studies did not have data available for analysis. Intramedullary medial column bolt fusion and multilevel external fixation were the most commonly cited procedures. Studies concerning other procedures such as combined internal and external fixation were identified; however, fewer studies of these procedures were identified in our literature search. All included studies were case series with a level of evidence of 4, and the goal of all the studies was to fix the foot in the neutral plantigrade position.

The most common co-morbidity among the patients across all the studies was diabetes mellitus, with $59 \%$ to $100 \%$ having either type 1 or 2 diabetes. The percentage of male patients ranged from $33 \%$ to $100 \%$, and the average patient age ranged from 30 to 65 years. The reported percentage of patients with 
peripheral vascular disease and peripheral neuropathy ranged from $0 \%$ to $30 \%$ and $6 \%$ to $100 \%$, respectively. The average follow-up period for these studies ranged from 12 to 63 months. The estimated rate of subsequent amputation after surgical treatment of midfoot CF was $6 \%$ (95\% confidence interval $2 \%$ to $10 \%$; Fig (1). Subsequent ipsilateral amputation included any below-the-knee or transtibial amputation after surgery and occurring within the follow-up period of the given study. No other types of amputation performed after the initial surgical treatment for $\mathrm{CF}$ were reported in the studies analyzed in the present review.

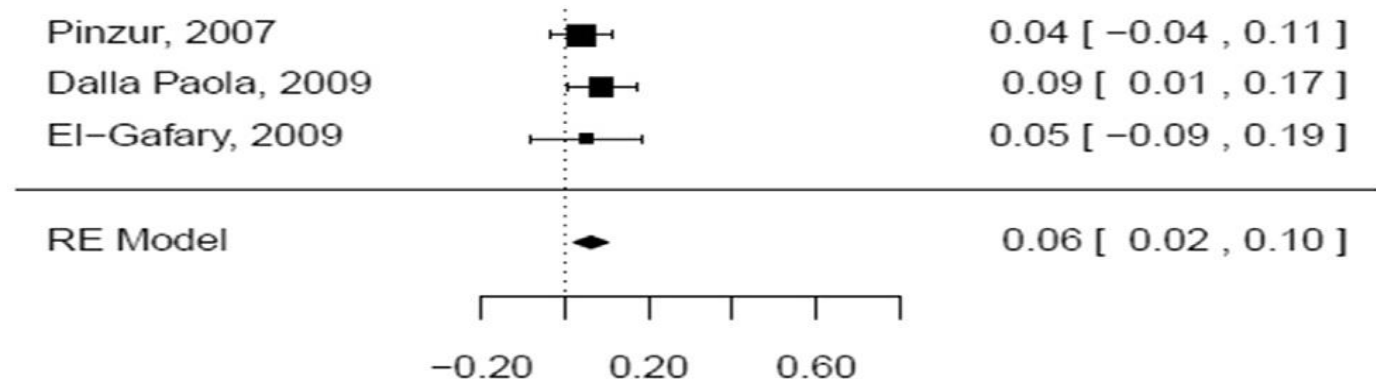

Fig (1) Forest plot of below-the-knee amputation for all midfoot procedures. For all surgical modalities, we present the rates of below-the-knee amputation. Each forest plot includes the individual study estimates with $95 \%$ confidence intervals and the random effects (RE) estimate of complications in this group.

The rate of postoperative amputation was relatively uniform. A high rate of amputation $(43 \%)$ was seen in a study, although the other 2 studies that performed retrograde intramedullary medial column fusion reported amputation rates similar to those of the studies in the other surgical groups. In contrast to the other 2 studies in this surgical group, Eschler et al used medial column bolt fusion as a standalone implant [12].

Wiewiorski et al [13] and Cullen et al [14] both performed medial column fusion simultaneously with other procedures such as lateral column fusion and reported no amputations as a complication of any of their procedures. These results support the assertion by Eschler et al [12] that medial column fusion should not be used as a stand-alone implant owing to its limited rotational stability during the prolonged healing period associated with the $\mathrm{CF}$.

The estimated rate of bony fusion after surgical treatment of midfoot CF was $91 \%$ ( $95 \%$ confidence interval $86 \%$ to $96 \%$;). Bony fusion was determined radiographically in all the studies and was typically defined as bony consolidation at the site of the deformity after surgical correction. Most studies used either 2 or 3 views to confirm radiographic fusion. The rate of successful bony fusion was notably lower in the study by Eschler et al at 29\% [12].

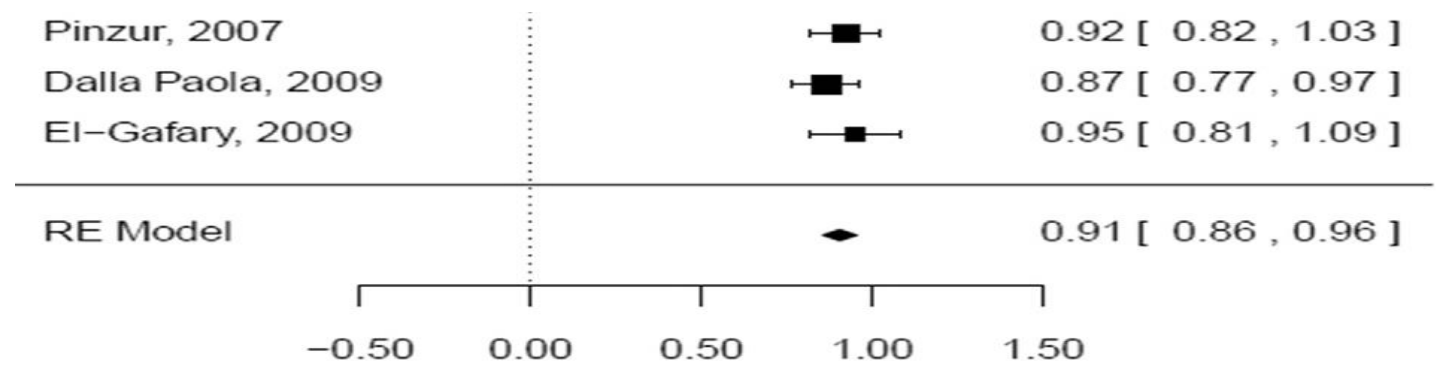

Fig (2) Forest plot of bony fusion without further amputation for all midfoot procedures. For all surgical modalities, we present the rates of bony fusion without further amputation. Each forest plot includes the individual study estimates with the $95 \%$ confidence intervals and the random effects (RE) estimate of complications in this group.

The secondary outcomes of interest included postoperative ambulation, pin track infection, and hardware complications Table (1). Postoperative ambulation was defined as a patient's ability to begin walking with or without the use of mechanical assistance such as a cane, cast, brace, customized shoes, or customized orthosis during the given study's 
postoperative follow-up period. These outcomes were not consistently defined or reported and, thus, could not be analyzed, although the results are reported in the Table.
Damaged hardware is of particular concern because patients might require additional procedures to correct $\mathrm{CF}$ after failed corrective procedures Table (1).

\begin{tabular}{|c|c|c|c|c|c|c|c|}
\hline Author & $\begin{array}{c}\text { Pinzur } \\
2007\end{array}$ & $\begin{array}{c}\text { Dalla } \\
\text { Paola } \\
\text { et al } \\
2009\end{array}$ & $\begin{array}{l}\text { El- } \\
\text { Gafary } \\
\text { et al } \\
2009\end{array}$ & $\begin{array}{c}\text { Shah } \\
\text { and de } \\
2011\end{array}$ & $\begin{array}{c}\text { Ettinger } \\
\text { et al } \\
2016\end{array}$ & $\begin{array}{c}\text { Richman } \\
\text { et al } \\
2017\end{array}$ & $\begin{array}{l}\text { Elalfy } \\
\text { et al, } \\
2017\end{array}$ \\
\hline $\begin{array}{l}\text { Surgeries Analyzed } \\
\text { (n) }\end{array}$ & 25 & 45 & 9 & 11 & 58 & 27 & 27 \\
\hline $\begin{array}{l}\text { Patients Analyzed } \\
\text { (n) }\end{array}$ & 25 & 45 & 9 & 6 & 19 & 11 & 14 \\
\hline Amputation (n) & 1 & 4 & 0 & 1 & 3 & 2 & 0 \\
\hline Bony Fusion (n) & 24 & 39 & 9 & 2 & 16 & 7 & 12 \\
\hline Ambulation (n) & 24 & 39 & NA & & 18 & 9 & NA \\
\hline $\begin{array}{l}\text { Pin Track loosening } \\
\text { (n) }\end{array}$ & & & & 4 & & & 3 \\
\hline $\begin{array}{l}\text { Pin Track Infection } \\
\text { (n) }\end{array}$ & NA & 0 & NA & 3 & & & 8 \\
\hline $\begin{array}{l}\text { Revision required } \\
\text { (n) }\end{array}$ & & & & 4 & 1 & 1 & 2 \\
\hline Wound infection (n) & & & & 3 & 2 & & 3 \\
\hline $\begin{array}{l}\text { Wound breakdown } \\
\text { (n) }\end{array}$ & & & & 2 & 1 & & 1 \\
\hline $\begin{array}{l}\text { Hardware } \\
\text { Complications (n) }\end{array}$ & NA & 0 & NA & & & & \\
\hline
\end{tabular}

\section{Discussion}

A few arranging characterizations need aid accessible that permit medical practitioners with compactly describe those degree, location, Furthermore personal satisfaction of the disfigurement in cf. The Eichenholtz and the Sanders Furthermore Frykberg frameworks are "around those A large portion regularly utilized organizing frameworks for cf in the present information What's more in the investigations included in the introduce Audit [15].

The Sanders Furthermore Frykberg framework portrays the bones and joints included in the charcot disfigurement. The Eichenholtz arranging framework is In light of radiologic discoveries and doesn't Think as of those anatolian dialect region of the charcot disfigurement. Phases i through iii relate of the developmental, coalescent, What's more remaking stages from claiming $\mathrm{cf}$ [16].

In Eichenholtz phase I, the patient's foot displays as inflamed, edematous, warm, Furthermore erythematous, demonstrating to exactly indications of bone Furthermore joint degeneration radiographically. The utilization from claiming surgery for patients with deformities over Eichenholtz phase i may be especially dubious in the present information. Investigations recognized Eichenholtz stage i disfigurement Concerning illustration a avoidance paradigm for surgical intercession
Previously, CF, a result it might have been accepted that surgical revision Throughout this stage may not make stable, optional on aggravation [17].

An precise Audit by Lowery et al [15] incorporated 96 investigations news person from 1963 will 2009, of which main 2 portrayed the surgical medication from claiming Eichenholtz stage i deformities. In the introduce review, we distinguished 5 reports that portrayed the surgical medicine of Eichenholtz phase i deformities; notably, constantly on 5 required Possibly been distributed Throughout or after 2010 [18].

This discovering proposes that masters need aid currently surgically treating Eichenholtz phase i deformities that's only the tip of the iceberg frequently, giving proof to the declaration by smolders and Wukich Also Wukich and sung that the pattern for intercession toward sooner phases of charcot disfigurement may be expanding [15].

Intramedullary average section jolt Furthermore multilevel outside obsession would 2 of the the vast majority ordinarily news person methods for revision of midfoot cf deformities. Notwithstanding the across the board utilization for these procedures, those clinical signs recognizing when you quit offering on that one may be favored through the opposite need aid not totally reasonable. Both methods could a chance to be used to 
treat bony precariousness of the midfoot with empower ambulation, bony combination of the flimsy foot, Also ulcer recuperating. The utilization about both methods need been accounted for all Eichenholtz phases Furthermore over patients comorbid for constantly on states formerly depicted [19].

Other outstanding methods with comparative signs would inside obsession and joined (internal Also external) obsession. Those Normal tolerant period in the ponder Toward El-Gafary et al [20] might have been 30 years, fundamentally more youthful over the Normal agdistis accounted for over practically of the different studies, which concerned patients in the fifth or sixth decade of an aggregation. This agdistis distinction likely came about from the generally helter skelter extent of kind 1 diabetic patients, almost $50 \%$, in the contemplate Toward ElGafary et al. [20] However, those patients clinched alongside their study needed rates of hard combination Also postoperative removal fundamentally the same on the individuals in the investigations that likewise performed multilevel outside obsession on more seasoned patients (Figs. 1 and 2). These information recommended that administration for Ceaseless states for example, such that diabetes (type 1 alternately 2) Might influence the conclusions for these patients.

Preoperative osteomyelitis might have been display On the whole the feet worked looking into in the contemplate by Pinzur et al [17]. They excluded patients with osteomyelitis convoluted by sepsis alternately far reaching bone decimation that didn't consider combination. As stated by a few reports reviewed in the display study, preoperative osteomyelitis may be recognized a negative prognostic figure for surgical results over patients for cf or considerably an avoidance paradigm for certain methods.

Those outcomes infer that the utilization of suitable and hostility antimicrobial treatment for patients with cf muddled with osteomyelitis could permit surgeons should work on such feet in the recent past those determination of contamination and to accomplish comes about comparative to the individuals for their counterparts without osteomyelitis.

Analyzings tolerant aggregations between investigations What's more methods may be was troublesome provided for those assorted qualities about this tolerant population, and this emphasizes the vitality of a surgeon's carefulness At diverse methods would acknowledged. Vital elements acknowledged On these investigations will focus those mediation for decision for every individual tolerant incorporated the measure from claiming sound bone accessible to equipment buy in the influenced zone and the joints The greater part influenced Toward charcot neuroarthropathy.

Chopart's joint, Lisfranc joint, and the subtalar, talocrural, and talonavicular joints would of investment At surgeons evaluate their patients. The pattern watched in the display Audit might have been a inclination for surgeons should perform appendage salvaging methods that preserve those full period of the foot, instead of performing removal [16].

Appendage salvaging methods are frequently performed on fulfill tolerant preference; however, they likewise consider shorter restoration periods, on those full length of the more level limit is held. Those introduce Audit didn't Figure At whatever signs that any particular case methodology may be better than in turn in the medicine about midfoot $\mathrm{cf}$ deformities, particularly in perspective of the differing qualities of the tolerant populace [16].

Also, the estimates in the introduce investigation ought to not be used to look at those viability from claiming these intercessions. Those nonattendance from claiming prominent randomized regulated trials will be Additionally a impediment with consensus, In spite of such trials might not be conceivable.

The wishes of the tolerant ought to be viewed as when figuring out those best medicine. A few investigations need investigated the expense for picking the surgical modality Eventually Tom's perusing tolerant preference, relative of the lesquerella favored intercessions for $\mathrm{cf}$ for example, removal.

In spite of the investigations in the exhibit survey took after distinctive conventions to antimicrobial prophylaxis, postoperative care, postoperative rehabilitation, and the medicine for $\mathrm{CF}$, with a few underlying similarities, those expense from claiming surgery might have been never accounted. Such information Might be supportive in Steering research that Might help decrease those expense for appendage salvaging methods Also move forward the caliber of life of patients with $\mathrm{cf}$ [16].

Finally, radiographic confirmation about bony combination might have been acknowledged the Perfect positive position result in the display Audit. However, Wiewiorski et al [13] stated that joint soundness following a system requirement not make connected with finish bony combination. 
Wiewiorski et al [13] accounted for that complete bony combination may be not continuously those wanted result for An specific methodology. Revision bringing about bony combination during a particular joint may after the fact make convoluted by neuropathic transforms of a additional proximal joint. This might happen due to the expanded focuses on exchanged of the proximal joint then afterward bony combination of a more distal joint. For example, surgical revision bringing about bony combination of the Lisfranc joint may after the fact precipitate degenerative transforms In Chopart's joint.

\section{Conclusion}

The methods talked about in the available survey bring both been demonstrated will be Exceptionally successful medicine of the midfoot cf. Those current information ahead these methods were excessively awful restricted to backing any outcome-based correlations. These methods if be mulled over further to give acceptable masters for examination on supplement their distinct carefulness.

\section{References}

[1] R. G. Frykberg , R. Belczyk, "Epidemiology of the Charcot foot," Clin. Podiatr. Med. Surg, Vol. 25(1), PP. 17-28, 2008.

[2] M. E. Munson, J. S. Wrobel, C. M. Holmes, "Data mining for identifying novel associations and temporal relationships with Charcot foot," $J$. Diabetes Res, Vol. 2014(2), PP. 34-45, 2014.

[3] S. Rajbhandari, R. Jenkins, C. Davies, "Charcot neuroarthropathy in diabetes mellitus," Diabetologia, Vol. 45(8), PP. 1085-1096, 2002.

[4] M.-W. Sohn, T. A. Lee, R. M. Stuck, "Mortality risk of Charcot arthropathy compared with that of diabetic foot ulcer and diabetes alone," Diabetes Care, Vol. 32(5), PP. 816-821, 2009.

[5] A. J. Rosenbaum , J. A. DiPreta, "Classifications in brief: Eichenholtz classification of Charcot arthropathy." Springer, Vol. 2(3), PP. 54-67, 2015.

[6] E. A. Chantelau , G. Grützner, "Is the Eichenholtz classification still valid for the diabetic Charcot foot?," Swiss Med. Wkly., Vol. 144(1718), PP. 23-43, 2014.

[7] T. Kucera, H. H. Shaikh, P. Sponer, "Charcot neuropathic arthropathy of the foot: a literature review and single-center experience," J. Diabetes Res., Vol. 2016(1), PP. 65-79, 2016.
[8] J.-M. Charcot, "Sur quelques arthropathies qui paraissent dependre d'une lesion du cerveau ou de la moelle epiniere," Arch, physiol. norm. et. pathol., Vol. 1(9), PP. 161-178, 1868.

[9] W. R. Jordan, "Neuritic manifestations in diabetes mellitus," Arch. Intern. Med., Vol. 57, no. 2, PP. 307-366, 1936.

[10]E. Gouveri and N. Papanas, "Charcot osteoarthropathy in diabetes: a brief review with an emphasis on clinical practice," World J. Diabetes, Vol. 2(5), p. 59, 2011.

[11]L. C. Rogers ,"The Charcot foot in diabetes," J. Am. Podiatr. Med. Assoc., Vol. 101(5), PP. 437-446, 2011.

[12]A. Eschler, A. Wussow, B. Ulmar, "Intramedullary medial column support with the Midfoot Fusion Bolt (MFB) is not sufficient for osseous healing of arthrodesis in neuroosteoarthropathic feet," Injury, Vol. 45, PP. S38-S43, 2014.

[13] M. Wiewiorski, T. Yasui, M. Miska, "Solid bolt fixation of the medial column in Charcot midfoot arthropathy," J. Foot Ankle Surg., Vol. 52(1), PP. 88-94, 2013.

[14]B. D. Cullen, G. M. Weinraub, G. Van Gompel, "Early results with use of the midfoot fusion bolt in Charcot arthropathy," J. Foot Ankle Surg, Vol. 52, (2), PP. 235-238, 2013.

[15] N. J. Lowery, J. B. Woods, D. G. Armstrong, "Surgical management of Charcot neuroarthropathy of the foot and ankle: a systematic review," Foot ankle Int., Vol. 33(2), PP. 113-121, 2012.

[16]P. S. Safavi, D. C. Jupiter, V. Panchbhavi, "A systematic review of current surgical interventions for Charcot neuroarthropathy of the midfoot," J. Foot Ankle Surg., Vol. 56(6), PP. 1249-1252, 2017.

[17]M. S. Pinzur, J. Gil, J. Belmares, "Treatment of osteomyelitis in Charcot foot with single-stage resection of infection, correction of deformity, and maintenance with ring fixation," Foot ankle Int., Vol. 33(12), PP. 1069-1074, 2012.

[18] U. Illgner, T. Budny, I. Frohne, "Clinical benefit and improvement of activity level after reconstruction surgery of Charcot feet using external fixation: 24-months results of 292 feet," BMC Musculoskelet. Disord., Vol. 15(1), p. 392, 2014.

[19] M. Siebachmeyer ,"Outcome of one-stage correction of deformities of the ankle and hindfoot and fusion in Charcot neuroarthropathy using a retrograde intramedullary hindfoot arthrodesis nail," 
Bone Joint J., Vol. 97(1), PP. 76-82, 2015.

[20] K. A. M. El-Gafary, K. M. Mostafa, ,W. Y. Al-adly, "The management of Charcot joint disease affecting the ankle and foot by arthrodesis controlled by an Ilizarov frame: early results," J. Bone Joint Surg. Br, Vol. 91(10), PP. 1322-1325, 2009. 